PHYSICAL EDUCATION AND SPORT

\title{
ИСТОРИЯ РАЗВИТИЯ МЕЖДУНАРОДНО- ПРАВОВОГО СОТРУДНИЧЕСТВА В СФЕРЕ СПОРТА И СТАНОВЛЕНИЕ МЕЖДУНАРОДНОГО СПОРТИВНОГО ПРАВА КАК ОТРАСЛИ МЕЖДУНАРОДНОГО ПРАВА, ОТРАСЛИ НАУКИ И УЧЕБНОЙ ДИСЦИПЛИНЫ
}

\author{
Фаррух Каюмов \\ соискатель Университета Мировой экономики и дипломатии, Узбекистан, Ташкент
}

DOI: https://doi.org/10.31435/rsglobal_ws/28022020/6929

\section{ARTICLE INFO}

Received: 20 December 2019

Accepted: 12 February 2020

Published: 28 February 2020

\section{KEYWORDS}

sport, international cooperation, international sports organizations, Olympic Games, International Olympic Committee.

\begin{abstract}
The article is devoted to the development of international cooperation in the field of sports. The author studies the main factors that influenced the formation of cooperation in this direction and identifies the main stages in its development. The author considers the development of international sports law not only as a branch of law, but also as a branch of science and academic discipline.
\end{abstract}

Citation: Фаррух Каюмов. (2020) Istoriya Razvitiya Mezhdunarodno-Pravovogo Sotrudnichestva v Sfere Sporta i Stanovlenie Mezhdunarodnogo Sportivnogo Prava kak Otrasli Mezhdunarodnogo Prava, Otrasli Nauki i Uchebnoj Discipliny. World Science. 2(54), Vol.1. doi: 10.31435/rsglobal_ws/28022020/6929

Copyright: (C) 2020 Фаррух Каюмов. This is an open-access article distributed under the terms of the Creative Commons Attribution License (CC BY). The use, distribution or reproduction in other forums is permitted, provided the original author(s) or licensor are credited and that the original publication in this journal is cited, in accordance with accepted academic practice. No use, distribution or reproduction is permitted which does not comply with these terms.

История физической культуры и спорта насчитывает тысячелетия. Она возникла около 40 тысяч лет до н.э. Физические упражнения и физическое воспитание явились теми главными факторами, которые способствовали выживанию человечества на заре его развития.[1]

С начала XIX в. зарождаются государственные формы военно-физического воспитания молодежи (станичные школы, кадетские корпуса, гимназии, юнкерские училища).[1]

Международный спорт как весомое социальное явление возник в конце XIX века. В этот период между отдельными государствами начинают устанавливаться международные контакты в различных сферах. [2]

Решающее значение в развитии международного сотрудничества в сфере спорта имело возрождение Олимпийских игр. Появление в XX в. Международного олимпийского комитета и Олимпийских игр повысило международную популярность спорта. Спорт начал играть одну из ключевых ролей в международных отношениях, и доказательством того служит его использование государствами в политических целях. Например, это может быть связано с желанием получить максимальное признание в соревнованиях. Однако, в $\mathrm{XX}$ в. международные спортивные мероприятия были идеологизированы и политизированы, что позволило использовать их как инструменты политического давления.

Так же, начиная с 1960-1970 гг., международный спорт подвергся существенной коммерциализации. С увеличением международного влияния Олимпийских Игр на статус 
государства, его имидж и положение на международной арене они оказались предметом соперничества государств не только в спортивном плане, но и в качестве одного из рычагов давления на внешнюю политику государства.[2]

К середине XX века было создано около ста международных спортивных объединений. Сегодня насчитывается свыше двухсот всемирных и региональных неправительственных организаций в области физического воспитания и спорта. [3]

В настоящее время спорт стал неотъемлемой частью международных отношений. Он выступает средством активизации международного сотрудничества, служит инструментом преодоления конфликтов и налаживания межкультурного диалога. [4]

Современный спорт представляет собой сложнейшую и специфичнейшую социальноэкономическую систему, разнообразные и разнохарактерные общественные отношения в которой призвано регулировать право. Поэтому сфера спорта, так же, например, как и банковской деятельности, требует на международном уровне специфического правового осмысления и качественной регламентации. Поэтому в настоящее время наблюдается процесс активного формирования комплекса норм, регулирующих международные отношения в области спорта. В научной литературе отсутствует единодушие в вопросе о его месте в системе права. Его можно рассматривать как комплексное по своей сути направление межгосударственного сотрудничества [5].

Современное международное право как общемировое достояние находится в состоянии постоянной эволюции и прогрессивного развития. В системе международного права появляются новые отрасли, осуществляется систематизация уже существующих отраслей, постоянно расширяется система международных нормативных правовых актов [6]. Идет определяемый реальными условиями международной жизни процесс выделения из международного права относительно автономных отраслей (подотраслей). Как правило, формирование отраслей международного права было объективным процессом, возникшим в реальной жизни, и вызывалось все более многогранным и многообразным характером отношений между субъектами международного права для наиболее эффективного регулирования обособившейся группы отношений в определенных сферах международной деятельности. Выделение отраслей международного права вызвано также появлением систем однородных международно-правовых норм, связанных одним предметом регулирования. Отрасли права складываются объективно, а устанавливаются наукой (как объективно существующие совокупности или определенные группы норм, составляющие обособленные и неотъемлемые объективные части общего международного права) [7].

Вышесказанное относится к международному спортивному праву. При этом, важный вклад в развитие международного сотрудничества в сфере спорта и формирование международных норм по вопросам спорта внесли международные спортивные движения.

О возникновении международных спортивных отношений мы можем утверждать в связи с зарождением в конце XIX века и дальнейшим развитием Международного спортивного движения (МСД). Мощным толчком к началу регулирования международных спортивных отношений в олимпийской сфере стало учреждение по инициативе Пьера де Кубертена летом 1894 года в Париже Международного олимпийского комитета (МОК). Таким образом, появление международного спортивного права можно соотнести с зарождением МСД и МОК.

В это же время начинают формироваться первые спортивные федерации. Международные спортивные федерации - это международные неправительственные организации, признанные Международным олимпийским комитетом (МОК). Как правило, это объединения по одному или нескольким видам спорта, представленным на мировой арене. Национальные федерации - члены таких ассоциаций, но обладают независимостью при определении форм и методов управления своим видом спорта. Однако международные ассоциации следят за тем, чтобы вся спортивная деятельность осуществлялась в соответствии с Олимпийской хартией [8]. Основными обязанностями международных спортивных федераций считается осуществление контроля за проведением систематических мировых спортивных мероприятий и управление этими мероприятиями. Это значит, что федерации следят за четностью игры, гарантируют регулярность проведения соревнований. Кроме того, федерации могут формулировать для МОК предложения и проекты документов по организации и управлению спортом. 
Данные субъекты МСП явились первыми творцами источников спортивного права. Спорт становится всеобщим явлением, и с каждым годом все больше людей вовлекается в спортивную деятельность. А международные спортивные организации, начиная с двадцатого столетия, стали играть все более важную роль в международных отношениях и стали рассматриваться в качестве одного из акторов. В современном мире они стали основным институтом развития международных спортивных связей. В современном мире международные спортивные организации можно рассматривать в качестве акторов не только спортивной дипломатии, но и международных отношений в целом.

Сегодня международные спортивные правоотношения в значительной степени развиваются в рамках олимпийского и параолимпийского движения [9]. Олимпийское движение включает: Международный олимпийский комитет (МОК), организационные комитеты Олимпийских игр $(\mathrm{OKOH})$, национальные олимпийские комитеты (НОКи), международные федерации (МФ), национальные ассоциации, клубы, атлеты, судьи, ассоциации и все организации и учреждения, признанные МОК [9]. Олимпийское движение образуют все субъекты права, которые соглашаются руководствоваться Олимпийской хартией и признают компетенцию МОК.

В истории МСП нельзя не отметить такую дату, как 30 июня 1984 года - день вступления в силу учредительных документов Спортивного арбитражного суда (CAC), созданного по инициативе МОК в Лозанне, позднее, в 1994 году, утвердившегося в своей независимости путем образования Международного арбитражного совета в области спорта, который обеспечивает соблюдение равенства прав сторон перед САС. Решения Международного спортивного арбитража являются также значимыми источниками МСП. Значительную роль в развитии спортивной юриспруденции сыграло право ЕС. Нашумевшее «дело Босмана» в середине 90-х гг. ХХ в., нанес шее удар по существующей системе переходов игроков в профессиональном футболе, поставило вопрос о соотношении актов спортивных федераций и норм национального и международного права не только в странах ЕС, но и в других государствах [9].

Таким образом, в истории развития данного сотрудничества можно выделить следующие этапы:

1. возрождение Олимпийских игр;

2. увеличение числа международных спортивных организаций;

3. повышение значения спортивной дипломатии, признание спорта в качества инструмента дипломатии со стороны ООН.

Следует отметить, что необходимость правового регулирования спортивных отношений была вызвана, прежде всего, растущей коммерциализацией профессионального спорта начиная с 80-х гг. XX в. Профессиональный спорт как сфера хозяйственной деятельности стал приносить доход, что привлекло все больший капитал в организацию и проведение спортивных соревнований. Выросли и доходы профессиональных спортсменов. Оформление трудовых правоотношений высокооплачиваемых спортсменов с клубами по игровым видам спорта стало проводиться с участием юристов, выступающих в роли агентов игроков. Большее значение в спортивных отношениях приобрели вопросы интеллектуальной собственности и использования масс-медиа, в частности права на фотографическое изображение спортсмена и на трансляции спортивных соревнований [9].

Одним из аспектов участия в международной спортивной деятельности для государства является укрепление его имиджа. Речь идет о проведении Олимпийских игр, мировых или европейских чемпионатах. Каждое государство, получающее возможность проведения соревнований мирового масштаба, старается организовать их таким образом, чтобы память о нем сохранилась как о благополучном и гостеприимном государстве. Это событие должно носить яркий и незабываемый характер. Безусловно, это связано с престижем государства и желанием закрепления своих позиций или улучшения их. Победа приносит государству престиж и признание. Принятие на своей территории такого рода мероприятий необходимо для реализации амбиций государства. В то же время проведение государством спортивных соревнований влечет не только затраты, но и выгоду, поскольку привлекает внимание инвесторов и приводит к росту туристических потоков со всего мира.

При этом, итоги международных соревнований зависят не только от успехов и фактических результатов спортсменов, но и от юридического толкования этих результатов и 
возникающих при этом коллизий. Качество выступления спортсменов на международных соревнованиях зависит также от правильной организации, в т. ч. от четкости процедуры, которой на сегодняшний день придается значение не меньшее, чем спортивным достижениям. В этой связи, и в том числе в условиях глобализации современного спорта, актуальность приобретает тема международного регулирования спортивного движения, его содержания и специфики, качества и эффективности [9].

Таким образом, основными факторами развития международного сотрудничества в сфере спорта и формирования МСП стали:

- развитие международных спортивных организаций;

- олимпийское движение;

- коммерциализация спорта;

- влияние спорта на имидж государства;

- повышение роли спортивной дипломатии.

Международное спортивное право (МСП) представляет собой систему взаимосвязанных норм и правил, регулирующих общественные отношения, складывающиеся в международной спортивной деятельности [4]. В свою очередь, международная спортивная деятельность включает в себя следующие основные направления:

1) организация и деятельность международных спортивных организаций, в том числе МОК, МСФ, ВАДА и др., включая их взаимодействие с национальными спортивными структурами;

2) организация и проведение международных спортивных соревнований, в том числе Олимпийских игр, а также иных международных спортивных и спортивно-зрелищных мероприятий;

3) международные отношения в сфере профессионального спорта, в том числе международное движение трудовых ресурсов в сфере спорта, включая международный трансферт, аренду, иные виды переходов спортсмена (тренера) из одного клуба в другой, а также международная деятельность спортивных агентов;

4) международная кооперация и иностранные инвестиции в сфере спорта;

5) международная коммерческая деятельность в сфере спортивной промышленности, в том числе организация совместных предприятий, производящих товары физкультурноспортивного и туристического назначения;

6) отношения, связанные с международной охраной прав интеллектуальной собственности в сфере спортивной деятельности;

7) международные налоговые отношения в сфере спорта;

8) травматизм в международном спорте;

9) всемирная антидопинговая политика и противодействие применению допинга в международном спортивном движении;

10) международное сотрудничество в борьбе с преступностью в сфере спортивной деятельности;

11) урегулирование международных спортивных споров;

12) другие сопутствующие и смежные с названными сферы деятельности.

Все названные направления выделяются своей однородностью и относительной обособленностью. Органический комплекс общественных связей, складывающихся между различными субъектами в указанных выше областях спортивной деятельности, представляет собой предмет регулирования международного спортивного права [7]. Нужно отметить, что объем международно-правовых норм, задействованных в процессе регулирования международной спортивной деятельности, постоянно увеличивается. МСП становится все более сложным и разветвленным [7].

Однако, хотя сам нормативный массив в данной области уже объективно существует, он довольно разрозненный и разбросан по различным международным и национальным нормативным актам, правовым системам и литературным источникам. Именно в международном спортивном праве особенно заметны существенные пробелы, свидетельствующие о его "мягкости" или даже некой "незрелости". Это касается и проблем международного движения трудовых ресурсов в сфере спорта, включая международный трансферт, аренду, иные виды переходов спортсмена (тренера) из одного клуба (спортивного общества) в другой, и международной деятельности спортивных агентов, и очевидного недостатка "структуродержащих" международно-правовых принципов, и недостаточности многосторонних механизмов и т. п. [7]. 
Вместе с тем, в настоящее время стали ощутимы скоординированные усилия государств в наведении дисциплины в отдельных вопросах функционирования международного спортивного движения. Государства все глубже осознают, что специализированные международно-правовые нормы и институты могут стать эффективным инструментом настройки и регулирования международных спортивных отношений. Все это и многое другое превращает международное спортивное право в один из важнейших и применяемых участков права и диктует необходимость его глубокого изучения, широкой пропаганды и активного совершенствования, и систематизации [7]. В целях его более четкого понимания и осмысления, а главное - грамотного применения на практике необходимы его обобщение, систематизация и, в конечном счете, формирование в структуре общего международного права комплексного правового образования - международного спортивного права (МСП). [7].

Ядро МСП составляют нормативные акты МОК, нормы которых, по сути, в значительной своей части универсальны и императивны. МОК представляет собой механизм, сопоставимый с функциями, образно говоря, мирового министерства спорта. В увязке с нормативными актами МОК создаются и существуют нормы, институты и субинституты многосторонних соглашений, касающихся спортивной проблематики и охватывающих различное количество государств. Кроме того, в МСП существуют нормативные комплексы, задействованные в регулировании международных спортивных отношений на региональном уровне (например, в ЕС). И в этой связи уже сегодня можно говорить о европейском спортивном праве как подотрасли международного спортивного права.

Важно подчеркнуть, что международное спортивное право как одна из важнейших структур современного международного права содержит как нормы международного публичного права, регулирующего прежде всего межгосударственные отношения (например, международное сотрудничество по борьбе с преступностью в сфере спорта), так и международного частного права, охватывающего отношения между частными лицами организациями и гражданами разной государственной принадлежности (например, продажи (трансферты) игроков зарубежным спортклубам) [7].

Наряду с отраслью международное спортивное право, которая регулирует соответствующие отношения, развивается наука спортивного права и дисциплина [1].

В отличие от спортивного права, регулирующего отношения в сфере физической культуры и спорта, наука спортивного права изучает закономерности правового регулирования физкультурно-спортивных отношений. Спортивно - правовая наука описывает, объясняет и прогнозирует правовые процессы и явления в области физической культуры и спорта. Она изучает содержание спортивно-правовых норм, необходимое для правильного и единообразного их применения и анализирует практику применения норм спортивного права физкультурно-спортивными организациями, спортивными арбитражными судами и органами исполнительной власти. Такие исследования необходимы для выявления закономерностей взаимодействия спортивно-правовых норм и регулируемых ими общественных отношений. [1].

Следует отметить, что наука спортивного права находится на стадии становления. Для ее развития необходимы соответствующие специалисты в сфере физической культуры и спорта и в первую очередь юристы.

Также следует отметить, что в настоящее время мало юридической литературы по вопросам физической культуры и спорта. Успешное функционирование специалистов в сфере физической культуры и спорта зависит, в частности, от знания ими правового регулирования этих отношений.

Кроме того, отсутствует правовая подготовка специалистов физической культуры в учебных заведениях, существуют проблемы, связанные с правовым воспитанием выпускников физкультурных высших учебных заведений. Поэтому и назрел вопрос о правовой подготовке специалистов физической культуры и спорта в учебных заведениях.

В связи с этим, важно изучить зарубежный опыт. Данный опыт преподавания спортивного права может быть успешно использован при внедрении аналогичных учебных курсов в образовательный процесс юридических и спортивных вузов республики, а также должностными лицами в области высшего профессионального образования для организации преподавания спортивного права в системе образования

В связи с этим, особый интерес представляет опыт Франции в этой сфере. Так, Научноисследовательский центр спортивного права (Марсель)) является составной частью Центра 
экономического права на факультете права и политических наук Экс-Марсель, который, в свою очередь, входит в состав Университета Поль Сезанн (Экс-Марсель III). Центр был организован на факультете права и политических наук Экс-Марсель 1 октября 2000 г. и осуществляет как базовую подготовку специалистов в области спортивного права (магистратура), так и непрерывную профессиональную подготовку, повышение квалификации [10].

Особого внимания заслуживает опыт Великобритании. Так, Юридический факультет Университета Ноттингем Трент предлагает магистерскую программу по спортивному праву (выпускник - LLM - магистр права) [11]. Образовательная подготовка включает изучение британского и международного (как глобального, так и региональногоевропейского) спортивного права. Некоторые модули могут использоваться для повышения квалификации уже практикующих специалистов в области спортивного права. [11].

Большое внимание преподаванию спортивного права уделяется в Швеции. В частности, Юридический факультет Университета Мальмё (Malmo University) реализует образовательную программу «Спортивное право и этика спорта». Учебный курс акцентирует внимание на проблемах правового регулирования спорта, но также затрагивает и более широкие (социологические, ценностные, экономические и др.) проблемы спорта. [12]

Следует отметить также Международный центр спортивного образования в Невшателе в Швейцарии. Международный центр спортивного образования был учрежден в 1995 году Международной федерацией футбольных ассоциаций (ФИФА), Университетом Невшателя (кантон Невшатель, Швейцария) совместно с городом и кантоном Невшатель. Университет выпускает магистров права со специализацией «спортивное право». Деятельность Международного центра спортивного образования ведется по трем основным направлениям: научные исследования, консалтинг и образование.

Не менее интересен опыт преподавания спортивного права в США. Так, школа менеджмента Айзенберг при Университете штата Массачусетс в городе Эмхёрст является одним из самых авторитетных учебных заведений США в области организации и правового регулирования спорта, управления спортом и спортивной индустрией. В рамках школы действует Факультет спортивного менеджмента [13]. Факультет спортивного менеджмента был создан в 1971 году. С тех пор его выпускниками стали свыше 3000 высококвалифицированных профессионалов в различных направлениях организации и управления спортивной деятельностью. Реализуются как программы бакалавриата, так и магистерские программы. Еще одним крупным образовательным центром в области спортивного права в США является Национальный институт спортивного права Школы права Университета Маркетт (Marquette University, Милуоки, штат Висконсин), [14] основанный в 1989 году. В отличие от вышеупомянутого факультета спортивного менеджмента Школы менеджмента Айзенберг, стремящегося обеспечивать самый широкий охват связанных со спортивной деятельностью и спортивной индустрией направлений подготовки и исследований, Национальный институт спортивного права сосредоточивается именно на тематике спортивного права, хотя и по самым его разнообразным направлениям. Юридический факультет Университета Тьюлейн (Tulane University Law School (Новый Орлеан, штата Луизиана, США)) также является одним из немногих университетских факультетов в США, выдающих дипломы об образовании по специализации «Спортивное право» [15]. На факультете действует управляемое наиболее активными студентами студенческое Общество спортивного права (Sports Law Society), которое регулярно устраивает встречи со значимыми фигурами в мире спорта и спортивного права для обсуждения актуальных юридических вопросов и проблем и часто спонсирует общественные программы, привлекая к этому ведущих спортивных адвокатов и бизнесменов. Каждый год Учебный суд Тьюлейн устраивает Национальное соревнование по учебным судебным процессам в рамках современных правовых проблем и вопросов, связанных с индустрией спорта. Резюме победителя ежегодно публикуется в «Журнале спортивных адвокатов». Студенты также принимают участие в ежегодном конкурсе переговоров в области спорта. Расположенный в НьюХейвен (штат Коннектикут, США) юридический факультет Йельского университета (Йельская школа права) реализует учебный курс «Спорт и право» [16]. Изучение производится по трехлетней программе J.D. (Juris Doctor - доктор Права) [10].

Спортивное право преподается в некоторых вузах РФ, в частности - в Московской государственной юридической академии им. О.Е. Кутафина. 
Данный опыт представляет большой интерес и для Республики Узбекистан. Таким образом, в заключение можно отметить, что развивать науку спортивного права и систему подготовки специалистов в области спортивного права.

Таким образом, перспективы развития международного спортивного права как отрасли права, как области научного правоведения, как учебной дисциплины в долгосрочной стратегии весьма обширны [1].

\section{REFERENCES}

1. Шашкова И. Спортивное право. Курс лекций. Витебск УО «ВГУ им. П.М. Машерова. 2012. - С. 12.

2. Зонова Т. В. Язык спорта универсален, как язык музыки // Сайт PCMД. 25.07.2012. URL: http://www.russiancouncil.ru/analytics-and-comments/analytics/yazyk-sporta-universalen-kak-yazyk-muzyki/

3. Сизова Е. Гуманитарные аспекты политики международного спорт. Автореферат диссерт. насоис. ст. к.п.н. - Москва, 2000. - С.1.

4. Мартыненко С.Е.Роль спортивной дипломатии в международных. отношениях и внешней политике. Автореферат. диссертации на соискание ученой степени кандидата исторических наук. Москва - 2015.

5. Захарова Л.И. Международное сотрудничество в области спорта // Международное публичное право: учеб. / Л.П. Ануфриева, Д.К. Бекяшев, К.А. Бекяшев, В.В.Устинов (и др.); отв. ред. Бекяшев К.А.- М.: Изд-во Проспект, 2009. С.936-939

6. Данилевич А. Понятие национального и международного спортивного права. [Эл. pecypc] URL: http://elib.bsu.by/bitstream/123456789/5879/1/danilevich_2009_1_IL_issues.pdf

7. Магденко А. Международное спортивное право: проблемы статуирования отрасли. // Правопорядок: история, теория, практика, 1 (1) 2013. - С.12

8. Алексеев С. В. Международное спортивное право: становление и перспективы развития//"Спорт: экономика, право, управление", 2008, N. 3 [Эл. ресурс] URL: http://center-bereg.ru/o4042.html

9. Олимпийская Хартия 2015 г. Официальный сайт Международного Олимпийского Комитета. URL: https://www.stillmed.olympic.org/Documents/olympic_charter_en.pdf65

10. Данилевич А. Понятие национального и международного спортивного права. [Эл. ресурc] URL: http://elib.bsu.by/bitstream/123456789/5879/1/danilevich_2009_1_IL_issues.pdf

11. Соловьев А.А., Понкин И.В. Преподавание спортивного права за рубежом / Комиссия по спортивному праву Ассоциации юристов России. - М., 2010. - 72 с.

12. LLM Sports Law // http://www.ntu.ac.uk/apps/pss/courses/cf/60358-1/10/LLM_Sports_Law.aspx (Последнее посещение 02.09.2010).

13. Malmö University (Sweden) // http://www.asser.nl/Default.aspx?site_id=11\&level1=139 06\&level2=13921 (Последнее посещение 02.09.2010).

14. http://www.isenberg.umass.edu/sportmgt/ (Последнее посещение 02.09.2010).

15. National Sports Law Institute's Mission Statement // (Последнее посещение 02.09.2010) http://law.marquette.edu/cgibin/site.pl?2130\&pageID=557

16. Academics // http://www.law.tulane.edu/tlsAcademicPrograms/index.aspx?id=3566 (Последнее посещение 02.09.2010).

17. Yale Law School: Sport and the Law Course // (USA) (Последнее посещение 02.09.2010) http://www.asser.nl/default.aspx?site_id=11\&level1=13906\&level2=13919\&level3=\&textid=36009 